\title{
ESTUDO DA GERAÇÃO DOS RESÍDUOS SÓLIDOS EM HOTEL
}

STUDY OF SOLID WASTE GENERATION IN A HOTEL

ESTUDIO DE LA GENERACIÓN DE RESIDUOS SÓLIDOS EN HOTEL

Bianca Peruchinn

Universidade Federal de Pelotas

bianca.peruchin@yahoo.com.br

Ana Luísa Lopes da Cunha Ferrão

Universidade Federal de Pelotas

alauisa@yahoo.com.br

Lucas Lourenço Castiglioni Guidoni

Universidade Federal de Pelotas

lucaslcg@gmail.com

Érico Kunde Corrêa

Universidade Federal de Pelotas ericokundecorrea@yahoo.com.br

Luciara Bilhalva Corrêa

Universidade Federal de Pelotas

luciarabc@gmail.com

Data de Submissão: 19/08/2014

Data de Aprovação: 23/04/2015

RESUMO: A problemática dos resíduos sólidos constitui um desafio. A caracterização dos resíduos sólidos e a determinação da sua composição gravimétrica estão entre as principais ferramentas de planejamento do manejo dos resíduos. Desta forma, este estudo teve como objetivo usar estas ferramentas para encontrar os principais fatores que determinam a geração dos resíduos em um hotel voltado para o turismo de negócios localizado no sul do Brasil. Foram realizadas quatro caracterizações durante os meses de maior ocupação do hotel em dias escolhidos para abranger a sazonalidade de hospedagem. Os resultados obtidos permitiram verificar que a categoria de resíduos gerados em maior quantidade é a matéria orgânica putrescível e que uma grande parcela da totalidade de resíduos gerados pode ser destinada para a reciclagem. Ainda, dentre os fatores que influenciam a geração dos resíduos estão o motivo da hospedagem, a realização de eventos, além da quantidade de pessoas presentes no estabelecimento - hóspedes, funcionários, pessoas extras e 
em eventos. Os resultados obtidos neste estudo são fundamentais para a construção, ampliação e/ ou melhoria do plano de gerenciamento dos resíduos sólidos, ferramenta que atualmente é exigida pela legislação brasileira para empreendimentos que geram grandes quantidades de resíduos, o que inclui o setor hoteleiro.

PALAVRAS CHAVE: Impacto ambiental no turismo. Hotelaria. Composição gravimétrica dos resíduos sólidos.

ABSTRACT: The issue of solid waste is a challenge. The characterization of solid waste, and the determination of gravimetric composition are among the main tools in waste management planning. These tools are used in this study, with the aim of finding the main factors that determine the generation of waste at a business tourism hotel in Southern Brazil. Four characterizations were carried out during the months of highest occupancy in the hotel, on days chosen to encompass the seasonality of accommodation. The results demonstrated that the category in which most waste is generated is perishable organic matter, and that a large portion of the waste generated can be sent for recycling. Moreover, among the factors that influence waste generation are the reason for the accommodation - hosting events - as well as the number of people using the establishment guests, workers, additional people, and events delegates. The results of this study are fundamental for drawing up, expanding and/or improving the solid waste management plan, a tool that is currently required under Brazilian law for companies that generate large amounts of waste, including accommodation establishments.

KEYWORDS: Environmental impact of tourism. Hotel Management. Gravimetric composition of solid waste.

RESUMEN: La problemática de los residuos sólidos constituye un desafío. La caracterización de los residuos sólidos y la determinación de su composición gravimétrica están entre las principales herramientas del plan de manejo de los residuos. De este modo, este estudio tuvo como objetivo usar estas herramientas para encontrar los principales factores que determinan la generación de los residuos en un hotel orientado al turismo de negocios ubicado en el sur de Brasil. Fueron realizadas cuatro caracterizaciones durante los meses de mayor ocupación del hotel, en días elegidos para abarcar la estacionalidad del hospedaje. Los resultados obtenidos permitieron verificar que la categoría de residuos generados en mayor cantidad es la materia orgánica putrescible y que una gran proporción de la totalidad de residuos generados puede ser destinada al reciclado. Por otro lado, entre los factores que influyen en la generación de los residuos están el motivo del hospedaje, la realización de eventos, además de la cantidad de personas presentes en el establecimiento huéspedes, empleados, personas extras y en eventos. Los resultados obtenidos en este estudio son fundamentales para la construcción, ampliación y/o mejoría del plan de gerenciamiento de los residuos sólidos, herramienta que actualmente es exigida por la legislación brasileña para emprendimientos que generan grandes cantidades de residuos, lo que incluye al sector hotelero.

PALABRAS CLAVE: Impacto ambiental en el turismo. Hotelería. Composición gravimétrica de los residuos sólidos. 


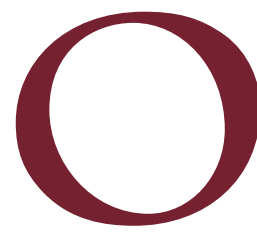

crescimento econômico registrado pelo Brasil nas últimas décadas alavancou a indústria do turismo. Em 2012, a oferta hoteleira no país superou 6.200 meios de hospedagem (BRASIL, 2013). A indústria hoteleira, devido ao caráter de suas funções, características e serviços, consome grandes quantidades de energia, água e produtos não duráveis e, por consequência, gera efluentes e resíduos. Dessa maneira, esse tipo de indústria torna-se fonte de impactos ambientais e sociais (ERDOGAN; BARIS, 2007; ALMEIDA, 2012).

Esta questão torna-se preocupante, uma vez que o país foi o anfitrião da Copa do Mundo em 2014, e será dos Jogos Olímpicos em 2016; o que tende a acelerar o crescimento do turismo e a implantação de um grande número de empreendimentos, tais como os meios de hospedagem. Diante desse cenário, ações e práticas que visem à redução dos impactos são necessárias, inclusive aquelas concernentes ao gerenciamento dos resíduos sólidos.

O manejo adequado dos resíduos sólidos possibilita a não geração e minimização da produção, fornece matéria-prima para indústrias de reciclagem e diminui as quantidades enviadas para disposição final em aterros sanitários (VERGARA; TCHOBANOGLOUS, 2012). Cabe, ainda, ressaltar a influência que as condições de saneamento básico detêm sobre a decisão do hóspede em relação ao destino turístico de preferência. Uma pesquisa conduzida por De Conto et al. (2011a) indica que práticas ambientais, incluindo a gestão de resíduos sólidos, são fatores que podem contribuir para a escolha da cidade a ser visitada e do meio de hospedagem. Nesse sentido, Jones, Hillier e Comfort (2014) completam que a gestão dos resíduos sólidos é um dos fatores que contribui para sustentabilidade na indústria hoteleira e beneficia, além dos proprietários, também os fornecedores, os clientes e a sociedade em geral.

É importante salientar que a geração de resíduos sólidos, além dos resíduos sólidos urbanos (RSU), abrange o que é gerado em estabelecimentos comerciais e prestadores de serviços, o que inclui os meios de hospedagem (BRASIL, 2010). No Brasil, a geração de RSU vem crescendo nos últimos anos, resultado do 
incremento do poder aquisitivo do brasileiro, bem como do seu padrão de consumo de bens - em 2012, o índice de geração chegou a 1,228 kg.hab-1 dia $^{-1}$ - e a disposição em aterros sanitários atingiu 105 mil ton.dia-1 (ABRELPE, 2013). Jacobi e Besen (2011) apontam que a sanção da Política Nacional dos Resíduos Sólidos (PNRS), Lei 12.305/2010 (BRASIL, 2010), trouxe a obrigatoriedade da criação e da implementação de um Plano de Gerenciamento dos Resíduos Sólidos (PGRS) para uma série de estabelecimentos, incluindo os meios de hospedagem, atrelado não somente pela periculosidade dos resíduos gerados, mas pela quantidade e volume do resíduo produzido. Em virtude destes fatos, a intensa geração de resíduos sólidos torna seu gerenciamento de fundamental importância para os empreendimentos que visam, além de reduzir gastos, entrar em concordância com a legislação vigente e assegurar a proteção à saúde pública e ao meio ambiente.

Segundo Murphy e Pincelt (2013), um melhor entendimento das quantidades e das composições dos resíduos produzidos é um passo fundamental para redução da geração e para aumentar a eficiência das demais etapas que envolvem o gerenciamento dos resíduos. Dessa forma, torna-se importante para os meios de hospedagem identificar e conhecer os resíduos sólidos que são gerados nas suas atividades mediante a metodologia da caracterização qualiquantitativa, para que possam estimar medidas de redução, reutilização, reciclagem e manejo dos resíduos, bem como construir, planejar, implementar e monitorar o seu próprio PGRS, atendendo a legislação brasileira e a sustentabilidade do meio ambiente. Pereira e De Conto (2008) afirmam que a geração de resíduos sólidos vem se tornando um dos maiores problemas de empreendimentos turísticos, o que torna necessário um manejo e planejamento adequado para essa problemática.

Destaca-se que nos meios de hospedagem existem fatores significantes que interferem na geração dos resíduos sólidos, tais como: número de hóspedes, número de funcionários, classificação do hotel, serviços oferecidos pelo empreendimento, faixa etária e poder aquisitivo dos hóspedes, motivo da hospedagem, quantidade de fontes geradoras, área relativa de geração de resíduos em jardins e parques (DE CONTO, 2005). O objetivo desse estudo foi determinar a composição gravimétrica dos resíduos sólidos gerados em um 
meio de hospedagem voltado para o turismo de negócios, situado em um município do Estado do Rio Grande do Sul, possibilitando a identificação de fatores que interferem na geração de resíduos e visando à melhoria contínua do PGRS, bem como das políticas ambientais do empreendimento.

METODOLOGIA

O trabalho foi desenvolvido no Município de Pelotas, que possui a terceira maior população do Estado do Rio Grande do Sul. Na cidade destaca-se o turismo comercial, de negócios, de lazer e cultura, que visam valorizar a participação histórica da cidade e a região de Costa Doce.

O meio de hospedagem investigado está na categoria de médio porte, prevalecendo o turismo de negócios. Possui uma área construída de aproximadamente $6800 \mathrm{~m}^{2}$, com 74 unidades habitacionais (UH), incluindo garagem, Conta com 31 funcionários e oferece os seguintes serviços: ambientes de estar, café da manhã, garagem coberta, lavanderia, manutenção, mensageiros, office, piscina, quartos adaptados para portadores de necessidades especiais, sala de ginástica, salas de convenções, salão de festas e sauna.

\section{IDENTIFICAÇÃO DAS FONTES GERADORAS DE RESÍDUOS}

Para a identificação das fontes geradoras de resíduos do empreendimento, foi utilizada como principal instrumento a observação direta nos diferentes setores do meio de hospedagem (MARCONI; LAKATOS, 2008). Desta forma, por meio do acompanhamento do setor de limpeza durante o trajeto de coleta interna dos resíduos foi possível determinar os setores geradores, conforme mostra a Figura 1. 
Figura 1 - Fluxograma dos setores geradores de resíduos de acordo com o trajeto para coleta interna dos resíduos no meio de hospedagem.

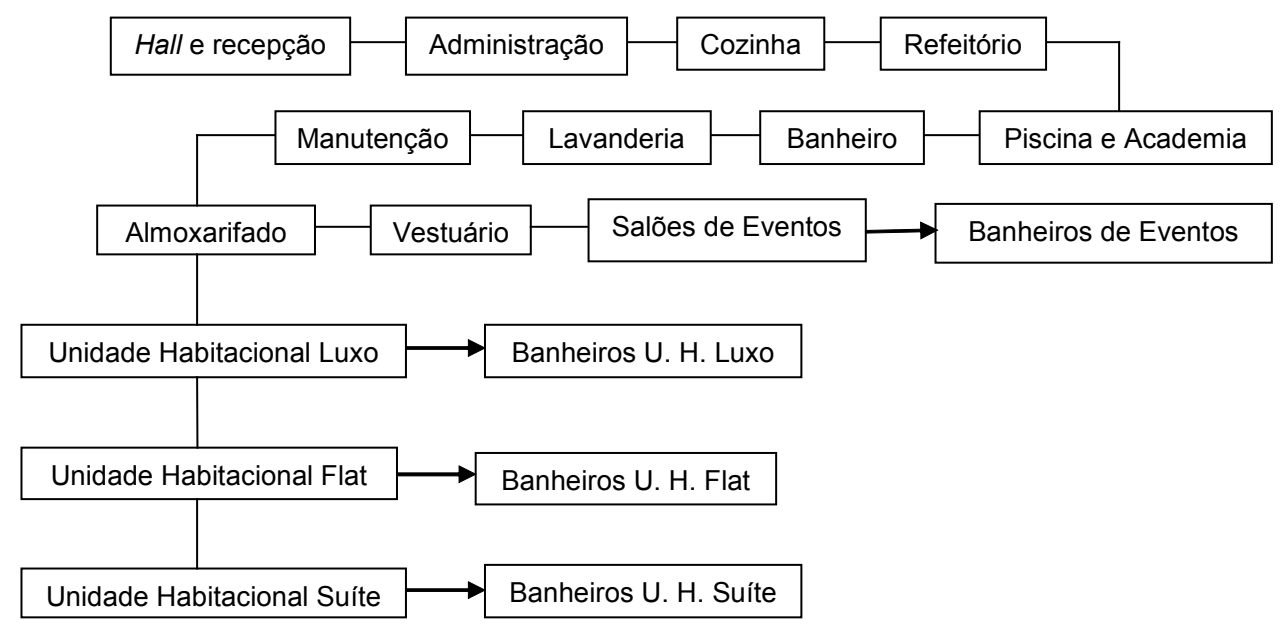

Fonte: Elaboração dos autores.

\section{DETERMINAÇÃO DA COMPOSIÇÃO GRAVIMÉTRICA}

Um estudo de caracterização de resíduos quantifica os seus componentes em relação ao seu peso e às frações que o compõem (AL-JARALLAHA; ALEISA, 2014). Para a realização do estudo foram identificados os meses que compreendiam o período de alta temporada de ocupação do meio de hospedagem - agosto e setembro. Sendo assim, para a coleta das amostras foram escolhidas duas semanas de cada mês, e em cada semana foi selecionado um dia para atender ao fluxo sazonal de hóspedes (dias de maior e menor ocupação), totalizando, assim, quatro caracterizações nos meses de agosto e setembro do ano de 2012.

Os resíduos gerados durante um dia inteiro foram coletados e acumulados no local de armazenamento interno do hotel, para que fossem caracterizados no dia posterior. Sendo assim, a amostra caracterizada era representativa à geração de resíduos de um dia inteiro de atividade do hotel. Foram deixadas etiquetas com os colaboradores responsáveis pela coleta dos sacos de resíduos sólidos, para que os sacos fossem identificados no momento da coleta e, dessa forma, no momento da caracterização, a sua procedência pudesse ser analisada.

Para realizar a caracterização dos resíduos, os sacos foram dispostos sobre uma lona plástica e abertos e, então, os diversos componentes foram agrupados e pesados individualmente por categoria e setor. 
Os resíduos presentes nas amostras coletadas no meio de hospedagem foram classificados pela Tabela 1, de acordo com as categorias propostas por De Conto (2009).

Tabela 1 - Exemplos de componentes presentes em cada categoria dos resíduos sólidos

\begin{tabular}{|c|c|}
\hline Categoria & Resíduos presentes \\
\hline $\begin{array}{l}\text { Matéria orgânica } \\
\text { putrescível }\end{array}$ & $\begin{array}{l}\text { Restos alimentares de origem animal e vegetal (cascas de frutas, erva-mate, preparo } \\
\text { da alimentação), podas de árvores, flores, folhas e grama. }\end{array}$ \\
\hline Plástico & $\begin{array}{l}\text { Sacos; sacolas; embalagens de refrigerantes, de água, de leite, de iogurte, de sorvete, } \\
\text { de margarina, de azeite, de biscoitos, de bombons; copos de água e café; isopor; } \\
\text { esponjas; papéis de balas; embalagens de cosméticos, de produtos de limpeza, de } \\
\text { engradados; cabide e pás de veneziana. }\end{array}$ \\
\hline Papel e papelão & $\begin{array}{l}\text { Caixas de alimentos, de bebidas, de ovos, de filtro de café, de chá, de medicamentos; } \\
\text { jornais; revistas; sacolas (principalmente oriundas de feiras de negócios) e livros. }\end{array}$ \\
\hline Vidro & $\begin{array}{l}\text { Garrafas de bebidas (cerveja, vinho), copos, embalagens de produtos alimentícios e } \\
\text { de medicamentos. }\end{array}$ \\
\hline Metal $t$ & Enlatados de produtos alimentícios, palha de aço e tampas. \\
\hline Metal $r$ & oebidas, de leite e achocolatados. \\
\hline Madeira & Amostras de madeira oriundas de feiras de negócios, caixas e palit \\
\hline $\begin{array}{l}\text { Panos, trapos, } \\
\text { couro e borracha }\end{array}$ & $\begin{array}{l}\text { Restos de tecido provenientes da secadora, velcro, peças de vestuário, pedaços de } \\
\text { tecido, panos de limpeza, luvas e touca. }\end{array}$ \\
\hline $\begin{array}{l}\text { Contaminante } \\
\text { químico }\end{array}$ & $\begin{array}{l}\text { Pilhas, tinta de sapato, embalagens de medicamentos, embalagens pressurizadas, } \\
\text { embalagens de veneno, panos impregnados com produtos químicos, canetas com } \\
\text { tinta, cosméticos em geral e lâmpadas. }\end{array}$ \\
\hline $\begin{array}{l}\text { Contaminante } \\
\text { biológico }\end{array}$ & $\begin{array}{l}\text { Papel higiênico, guardanapos, cotonetes, perfuro-cortantes (agulhas, seringas, } \\
\text { ampolas, lâminas de depilação e barbear), palitos de dente, fraldas e absorventes. }\end{array}$ \\
\hline Misto & $\begin{array}{l}\text { Embalagem longa vida (leite, suco, entre outros), blister, embalagens laminadas de } \\
\text { alimentos (salgadinhos, café, biscoitos), embalagem papel A4, fita adesiva, crachá, } \\
\text { mouse pad, fiação, embalagem de pasta de dente, papel alumínio, isqueiro e esponja } \\
\text { de limpeza. }\end{array}$ \\
\hline Diversos & $\begin{array}{l}\text { Pontas de cigarro, restos de sabonete e sabão, rolhas, fita de impressora, papel } \\
\text { carbono, prendedor de roupa, escovas de dente, cartão telefônico, protetor auricular, } \\
\text { filtros de água, raio-x, fitas k- } 7 \text { e porcelana. }\end{array}$ \\
\hline
\end{tabular}

Fonte: De Conto (2009).

Após a pesagem dos resíduos, foram realizados a sistematização dos dados e o cálculo da composição gravimétrica. Ainda, por meio do número de hóspedes e funcionários presentes no meio de hospedagem, das pessoas extras e em eventos e da quantidade total de resíduos gerada, foi calculada a geração per capita de resíduos de cada uma das quatro caracterizações, além da geração per capita média. 


\section{RESULTADOS E DISCUSSÃO}

A Tabela 2 aponta a quantidade total de resíduos gerados; o número de hóspedes, funcionários e pessoas extras e em eventos; e o resultado do cálculo da produção per capita de resíduos (Kg.pessoa-1.dia-1) das quatro caracterizações.

Tabela 2 - Total de resíduos gerados, número total de pessoas, produção per capita de resíduos e média dos dados das caracterizações do meio de hospedagem no período de alta temporada

\begin{tabular}{|c|c|c|c|c|c|c|}
\hline Variável & Caract.1 & Caract. 2 & Caract.3 & Caract.4 & Total & Média \\
\hline Quantidade de resíduos (Kg) & 37,910 & 21,238 & 58,767 & 33,316 & 151,231 & 37,808 \\
\hline Número de hóspedes & 40 & 27 & 57 & 53 & 177 & 44,25 \\
\hline Número de funcionários & 25 & 20 & 25 & 27 & 97 & 24,25 \\
\hline $\begin{array}{l}\text { Número de pessoas extras e em } \\
\text { evento }\end{array}$ & 19 & 25 & 80 & 1 & 125 & 31,25 \\
\hline Número total de pessoas no hotel & 84 & 72 & 162 & 81 & 399 & 99,75 \\
\hline $\begin{array}{l}\text { Produç̧ão per capita (Kg.pessoa- } \\
{ }^{1} \text { dia }^{-1} \text { ) }\end{array}$ & 0,451 & 0,295 & 0,363 & 0,411 & - & 0,379 \\
\hline
\end{tabular}

Fonte: Elaboração dos autores.

A maior quantidade de resíduos foi gerada na caracterização 3, considerandose o maior número de hóspedes e pessoas envolvidas em eventos.

Pode-se notar que a produção per capita não depende apenas do número de hóspedes, mas também do número de funcionários, do número de pessoas envolvidas em eventos e, ainda, do tipo de evento que ocorreu no hotel, bem como do motivo da hospedagem. Em média, no período de alta ocupação do meio de hospedagem, a geração per capita de resíduos foi de 0,379 Kg.pessoa-1. dia $^{-1}$, valor abaixo da quantidade gerada pelos brasileiros diariamente - de 1,228 Kg.hab-1, o que pode estar atrelado ao fato de apenas uma refeição ser servida no 
empreendimento, o café da manhã, e também devido à característica do meio de hospedagem de negócios, em que muitos hóspedes estão a trabalho e acabam por ficar pouco tempo no meio de hospedagem, gerando menos resíduos.

Sbert e et al. (2013) em um estudo na Ilha de Menorca, na Espanha, com dados da geração de resíduos sólidos ao longo de 10 anos, estimam valores de geração 13\% menores para turistas do que para os residentes. Em seu trabalho, o autor salienta que a geração de resíduos pelos turistas é uma informação importante para as demais etapas do gerenciamento dos RSU, como para o serviço público de limpeza, empresas de coleta e reciclagem.

Os resíduos encontrados no meio de hospedagem no período das caracterizações e a sua composição gravimétrica são apresentados na Tabela 3.

Tabela 3 - Composição gravimétrica dos resíduos gerados no meio de hospedagem no período de alta temporada

\begin{tabular}{|c|c|c|c|c|}
\hline Categorias & $\begin{array}{l}\text { Caracterização } \\
1 \text { (\%) }\end{array}$ & $\begin{array}{l}\text { Caracterização } \\
2(\%)\end{array}$ & $\begin{array}{l}\text { Caracterização } \\
3(\%)\end{array}$ & $\begin{array}{l}\text { Caracterização } \\
4(\%)\end{array}$ \\
\hline Matéria Orgânica Putrescível & 46,51 & 55,74 & 52,86 & 41,80 \\
\hline Plástico & 10,77 & 10,26 & 11,31 & 11,65 \\
\hline Papel e Papelão & 12,35 & 9,00 & 11,06 & 11,02 \\
\hline Vidro & 1,02 & 0,71 & 1,43 & 8,15 \\
\hline Metal Ferroso & 0,06 & 0,02 & 0,00 & 0,05 \\
\hline Metal Não Ferroso & 0,37 & 0,77 & 0,71 & 1,04 \\
\hline Pano, Trapo, Couro, Borracha & 2,43 & 1,24 & 2,26 & 1,73 \\
\hline Madeira & 0,06 & 0,00 & 0,00 & 2,13 \\
\hline Contaminante Químico & 1,04 & 0,27 & 3,02 & 0,34 \\
\hline Contaminante Biológico & 9,84 & 14,44 & 11,53 & 15,43 \\
\hline Misto & 3,39 & 6,24 & 5,10 & 4,50 \\
\hline Diversos & 12,16 & 1,32 & 0,73 & 2,16 \\
\hline
\end{tabular}

Fonte: Elaboração dos autores.

Comparando-se as Tabelas 2 e 3, é constatado que a matéria orgânica apresenta a maior fração, independente do fluxo sazonal de hóspedes e eventos. Cabe salientar, quanto a essa categoria, que a caracterização 2 obteve o maior percentual na composição gravimétrica, e a caracterização 3 foi a que teve a maior quantidade de resíduos desta categoria caracterizados - mais de $31 \mathrm{Kg}$. Este fato deveu-se ao acontecimento de dois eventos - coquetéis - ocorridos no 
meio de hospedagem nesta semana, o que explica a geração desta quantidade de matéria orgânica putrescível, enquanto nas semanas das caracterizações 1 e 2, os eventos eram, respectivamente, concentração de jogadores de futebol e show room de roupas, com uma geração de matéria orgânica putrescível em menor quantidade $-17,633 \mathrm{Kg}$ e $11,837 \mathrm{Kg}$, respectivamente.

Tratando-se dos números discrepantes nas categorias analisadas, a geração de vidro foi maior na caracterização 4, referente ao consumo de garrafas de vinho e cerveja, a qual se justifica por parte dos hóspedes estarem na cidade para uma formatura. Outro dado relevante é a geração de contaminante químico na caracterização 3, maior que as demais semanas devido à substituição de lâmpadas queimadas quando houve uma queda de energia que atingiu o empreendimento no período. Quanto à geração de componentes diversos ter sido maior na caracterização 1 , justifica-se por ter sido encontrado um par de sapatos e uma quantidade considerável de resíduos oriundo da varrição após a concentração dos jogadores. Na semana da caracterização 4, no setor da manutenção, houve uma maior quantidade de geração de madeira, o que não ocorreu nas demais semanas. Pereira e De Conto (2008) verificaram que, frequentemente, a composição gravimétrica dos resíduos sólidos não é estudada em eventos, às vezes sequer pensada, o que acaba por prejudicar o seu planejamento e a imagem ambiental. Já Balduino, Balduino e Menezes (2011) comentam que o setor de eventos vem ganhando espaço na hotelaria, e a qualidade dos serviços prestados é relevante na escolha do local onde um evento será realizado - sendo este evento realizado dentro do hotel ou na mesma cidade onde esse se localiza - tornando-se um fator de competitividade e escolha não apenas pelo atendimento às políticas públicas e à legislação, mas também ao quesito sustentabilidade.

A falta de planejamento nos hotéis quanto ao gerenciamento dos resíduos produzidos advindos dos serviços prestados a eventos pode vir a impactar de forma negativa a sua imagem, principalmente, quando hóspedes ou convidados do evento são expostos à segregação inadequada, problemas em relação ao acondicionamento, aumento no volume de resíduos, falta de capacidade para o armazenamento temporário dos resíduos e a consequente falta de comprometimento com a coleta seletiva dos resíduos. Esses fatores 
ISSN: 1983-7151

são provocados pelo crescimento da geração de resíduos, que está atrelado às características deste tipo de atividade: aumento no número de pessoas presentes no hotel, disponibilidade de alimentos e bebidas; materiais utilizados para a decoração do ambiente, o que traz a necessidade de o hotel prover uma estrutura de gerenciamento que atenda essa situação, somando-se a produção cotidiana, tendo em vista um adequado gerenciamento dos resíduos sólidos no estabelecimento.

Após coletados no perímetro interno do meio de hospedagem, é importante que os materiais sejam armazenados em um local apropriado até a próxima etapa, seja ela realizada por empresa, cooperativa ou serviço público. Porém, é comum, em meios de hospedagem, que as plantas arquitetônicas não considerem um espaço para este armazenamento no momento de seu planejamento, sendo frequentemente utilizados locais improvisados, podendo comprometer a segregação dos resíduos e as condições adequadas de higiene (DE CONTO et al., 2011b). Em relação ao presente trabalho, os valores encontrados para a geração de resíduos sólidos possibilitam estimar o espaço suficiente para o armazenamento interno dos resíduos e dos rejeitos gerados no período de alta ocupação no meio de hospedagem em questão. É importante frisar que o estabelecimento pesquisado não possuía local específico para o armazenamento interno dos resíduos, sendo este realizado na garagem do hotel. Para De Conto, Corrêa e Zaro (2013), informações relativas à tipologia e à quantidade de resíduos gerados nos meios de hospedagem são necessárias para a definição dos espaços de armazenamento dos mesmos ainda durante a concepção do projeto arquitetônico.

Outra pesquisa, conduzida por De Conto et al. (2006), informa que a maior parte dos meios de hospedagem consultados tem interesse em compostar seus resíduos orgânicos nas mediações do próprio empreendimento. Devido à grande quantidade de matéria orgânica putrescível produzida, a segregação deste resíduo permite a adoção da compostagem como tratamento, que favorece a gestão ambiental do meio de hospedagem, reduz a quantidade de resíduos sólidos que são enviados para aterros sanitários, prolonga a vida útil destes, além do benefício de utilizar o composto produzido na jardinagem do próprio meio de hospedagem. Além disso, a PNRS prevê que sejam promovidas 
alternativas de tratamento aos resíduos para o seu reaproveitamento e reciclagem, ao destinar a aterros sanitários apenas o rejeito (BRASIL, 2010).

Silva (2007) destaca a importância da utilização de equipamentos apropriados para a coleta e separação dos resíduos, áreas específicas para o seu armazenamento, implantação de programas de reciclagem e compostagem e, ainda, o conhecimento sobre os impactos que a geração excessiva de resíduos sólidos pode causar ao meio ambiente. Ressalta-se, aqui, a importância do estudo da composição gravimétrica dos resíduos no período de alta ocupação do hotel, visto que, desta forma, é possível dimensionar os dispositivos de acordo com a demanda máxima do empreendimento, o que evitará o subdimensionamento de coletores de acordo com a ocupação do hotel e proporcionará uma maior efetividade da segregação dos resíduos. Kirk (1995) salienta que a gestão ambiental, não necessariamente, implica um aumento de custos para o empreendimento hoteleiro e que, no caso de um gerenciamento inadequado dos resíduos sólidos, um programa de manejo correto dos mesmos pode, inclusive, gerar economia com a não geração de resíduos e a segregação daqueles gerados - processo que deve ser implantado com programas de treinamento dos colaboradores e de iniciativas simples e de baixo custo.

A identificação dos sacos de resíduos para a realização da sua caracterização permitiu identificar a procedência dos mesmos em relação a cada setor que gera resíduo no hotel. A Figura 2 traz o gráfico que compara a geração de resíduos das quatro caracterizações de acordo com os setores geradores. Nos dias anteriores às quatro caracterizações, a Unidade Habitacional Suíte não foi ocupada, não havendo resíduos neste setor, bem como no seu respectivo banheiro.

A Figura 2 representa a quantidade total de resíduos gerados em cada setor. Observa-se que o setor que mais gera resíduos é a cozinha - onde a matéria orgânica putrescível é gerada em maior quantidade, havendo uma relação direta entre a quantidade total de resíduos produzidos em cada caracterização e a quantidade gerada no setor da cozinha - a caracterização 3, que teve a maior quantidade de resíduos, também foi o dia que apresentou a maior quantidade de resíduos nesse setor. Almeida (2012), em estudo com hotéis de uma cidade do Marrocos, também aponta o setor cozinha como principal fonte de resíduos, sendo comentada a necessidade de minimizar os desperdícios por meio da adoção 
de práticas para capacitar os funcionários envolvidos. Além disso, Pistorello e De Conto (2011) sugerem que cabe ao setor responsável pela maior geração de resíduos a preferência por produtos com menos embalagem ou com possibilidade de reutilização ou reciclagem. A segregação dos resíduos provenientes deste setor é essencial, visto que é o que mais contribui no total gerado pelo meio de hospedagem, para que assim seja possível adotar práticas de reciclagem destes resíduos. Além disso, Neves et al. (2008) afirmam que a composição diária dos resíduos gerados em cozinhas e restaurantes não é homogênea.

Em segundo lugar, os setores que mais geram resíduos são as unidades habitacionais e seus respectivos banheiros, ficando na frente do que é gerado no salão de eventos. É possível notar, ainda, que a quantidade de resíduos produzidos entre os setores diferencia-se entre si; porém, comparando-se um mesmo setor entre as quatro caracterizações, observa-se que não existem grandes discrepâncias além das já comentadas.

Diante desses dados, nota-se a importância de garantir as condições necessárias de dispositivos para acondicionamento (sacos e lixeiras) para que os resíduos sejam segregados, principalmente no setor em que são gerados em maior quantidade. Assim, sugere-se que na cozinha sejam disponibilizados coletores diferentes para cada resíduo (matéria orgânica, contaminante biológico, papel e papelão, plástico e vidro); e nas unidades habitacionais coletores com compartimento para descarte da matéria orgânica e outro para resíduos inorgânicos recicláveis e, ainda, outro coletor no banheiro da unidade habitacional (PISTORELLO; DE CONTO, 2011). É também importante socializar essas e demais informações acerca do gerenciamento dos resíduos sólidos no empreendimento, considerando uma forma de conscientizar os funcionários, os hóspedes e a sociedade sobre suas responsabilidades ambientais (DE CONTO et al., 2011a). 
Figura 2 - Geração de resíduos das quatro caracterizações nos setores do meio de hospedaqem

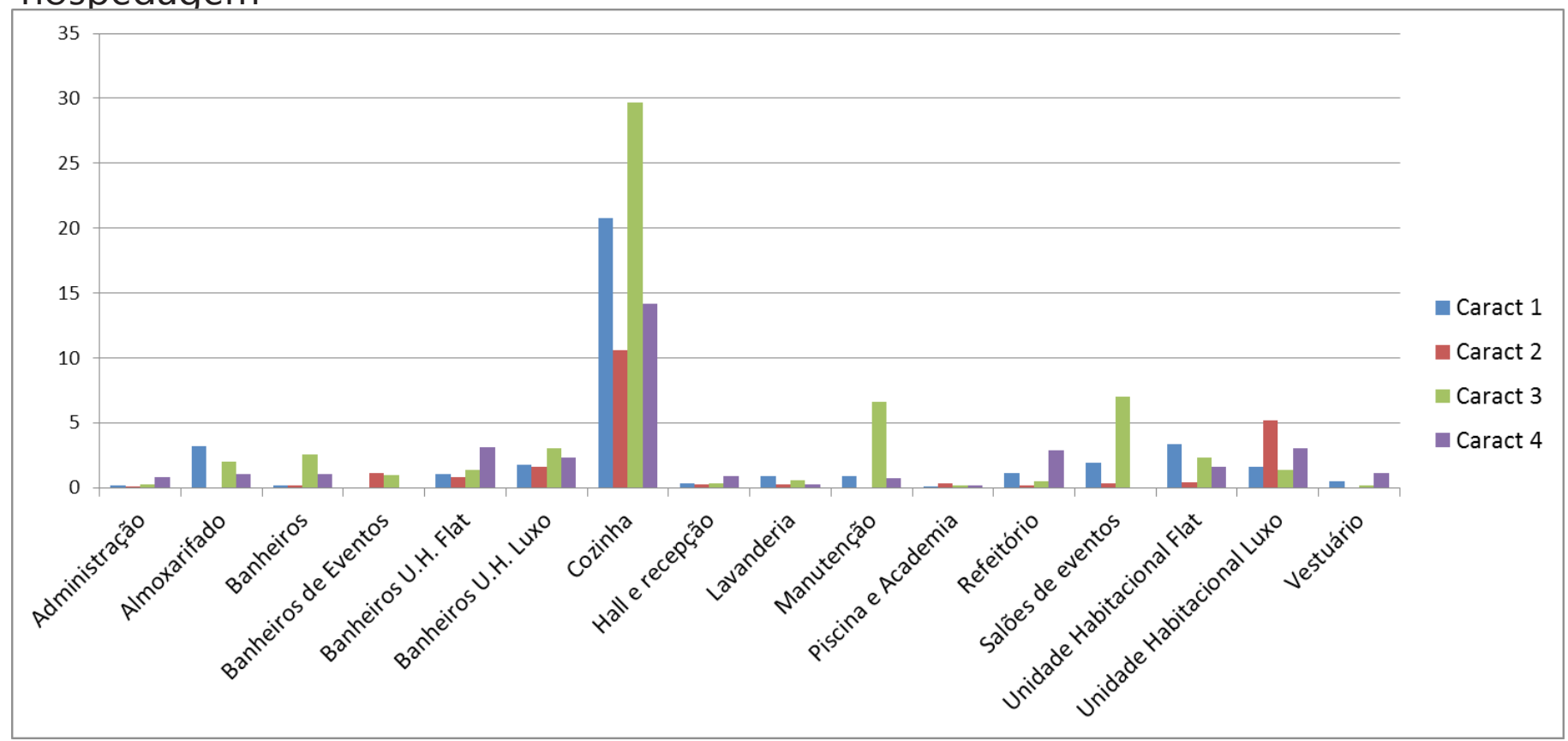

Fonte: Elaboração dos autores.

Os componentes presentes em cada categoria dos resíduos sólidos caracterizados no meio de hospedagem são listados na Tabela 4.

Tabela 4 - Componentes presentes em cada categoria dos resíduos sólidos caracterizados no meio de hospedagem no período de alta temporada

\begin{tabular}{ll}
\hline Categoria & Resíduos presentes \\
\hline $\begin{array}{l}\text { Matéria orgânica } \\
\text { putrescível }\end{array}$ & $\begin{array}{l}\text { Sobras/cascas do preparo de refeições, restos de refeições, erva-mate, filtro de } \\
\text { café, podas de jardim, arranjo de flores. }\end{array}$ \\
Plástico & $\begin{array}{l}\text { Sacos, sacolas, garrafa PET, copos, talheres, lacres, isopor, sachês, papel de } \\
\text { presente, embalagem de iogurte, biscoito, adoçante, potes de mel, embalagens } \\
\text { produtos de limpeza, de shampoo, cabide. }\end{array}$ \\
Papel e papelão & $\begin{array}{l}\text { Papel pardo e administrativo (folha A4); caixas de papelão, de bebida, de ovo, } \\
\text { de sapato; embalagens de pizza, de docinho, de chiclete, de chá; revista; jornal; } \\
\text { sacolas de compras e de feira de negócios. }\end{array}$
\end{tabular}

Vidro

Garrafas de bebidas (cerveja, vinho, espumante, whisbky), copos, xícaras, embalagens de produtos alimentícios e de medicamentos.

Metal ferroso Enlatados de produtos alimentícios, palha de aço, tampas e clips.

Metal não ferroso Maçanetas; latas de bebidas, de leite e achocolatados.

Madeira Caixas de hortifrúti, de charuto; palitos de fósforo e tábuas. 
Panos, trapos, couro e borracha

Contaminante químico

Contaminante biológico

Misto

Diversos
Filtro de tecido provenientes da secadora, pano de limpeza, corda, peças de tecido, toalha, lençol, elásticos e carpete.

Pilhas; embalagens de medicamentos, de produtos químicos; canetas com tinta; cola bastão; cosméticos em geral e lâmpadas.

Papel higiênico, guardanapos, cotonetes, perfuro-cortantes (agulhas, seringas, ampolas, lâminas de depilação e barbear), palitos de dente, fraldas, absorventes, preservativos, luvas cirúrgicas.

Embalagem longa vida (leite, suco, entre outros), blister, embalagens laminadas de alimentos (salgadinhos, café, biscoitos, manteiga), embalagem papel A4, de desodorante, fita adesiva, fiação, embalagem de pasta de dente, papel alumínio, isqueiro, esponja de limpeza, brinquedos, maço de cigarros, plástico filme e papel alumínio.

Pontas de cigarro, restos de sabonete e sabão, rolhas, fita de impressora, papel carbono, prendedor de roupa, escovas de dente, porcelana, CD-ROM, velas, esponja para flores.

A composição gravimétrica média dos resíduos sólidos gerados no meio de hospedagem no período de alta temporada é apresentada na Figura 3. Observa-se que a matéria orgânica putrescível é o resíduo predominante, sendo responsável por aproximadamente $49 \%$ do total de resíduos produzidos. Em dois estudos realizados em cidades gaúchas, De Conto et al. (2005) e De Conto et al. (2009), em Canela e Caxias do Sul, respectivamente, trazem dados de hotéis com 35 e 90 unidades habitacionais, os quais também apresentam a matéria orgânica putrescível como fração de maior volume, com 72,85\% e $65,19 \%$, respectivamente. A diferença entre a porcentagem encontrada para a matéria orgânica pode estar relacionada à localização do meio de hospedagem, ao tipo de hospedagem predominante (lazer, negócios, entre outros), ao poder econômico do hóspede e a outros fatores, como a existência de jardim no empreendimento, que acaba por gerar uma quantidade maior de resíduos orgânicos devido às atividades de manutenção e poda.

Quanto à segunda maior categoria encontrada (12,37\%), foi o contaminante biológico, constituído principalmente de papel higiênico, guardanapos, fraldas e absorventes, oriundos na sua maior parte das unidades habitacionais do hotel e seus respectivos banheiros. Os guardanapos foram encontrados no setor da cozinha e de eventos. Em ambos os casos, na cozinha ou nas unidades habitacionais, além dos coletores, são necessários mecanismos para incentivar a segregação da matéria orgânica e do contaminante biológico com resíduos secos potencialmente recicláveis, uma vez que esses materiais possuem destinações diferentes. 
Figura 3 - Composição gravimétrica média dos resíduos sólidos do meio de hospedagem no período de alta temporada. *Metais Ferrosos não aparecem por compor apenas $0,03 \%$ do total

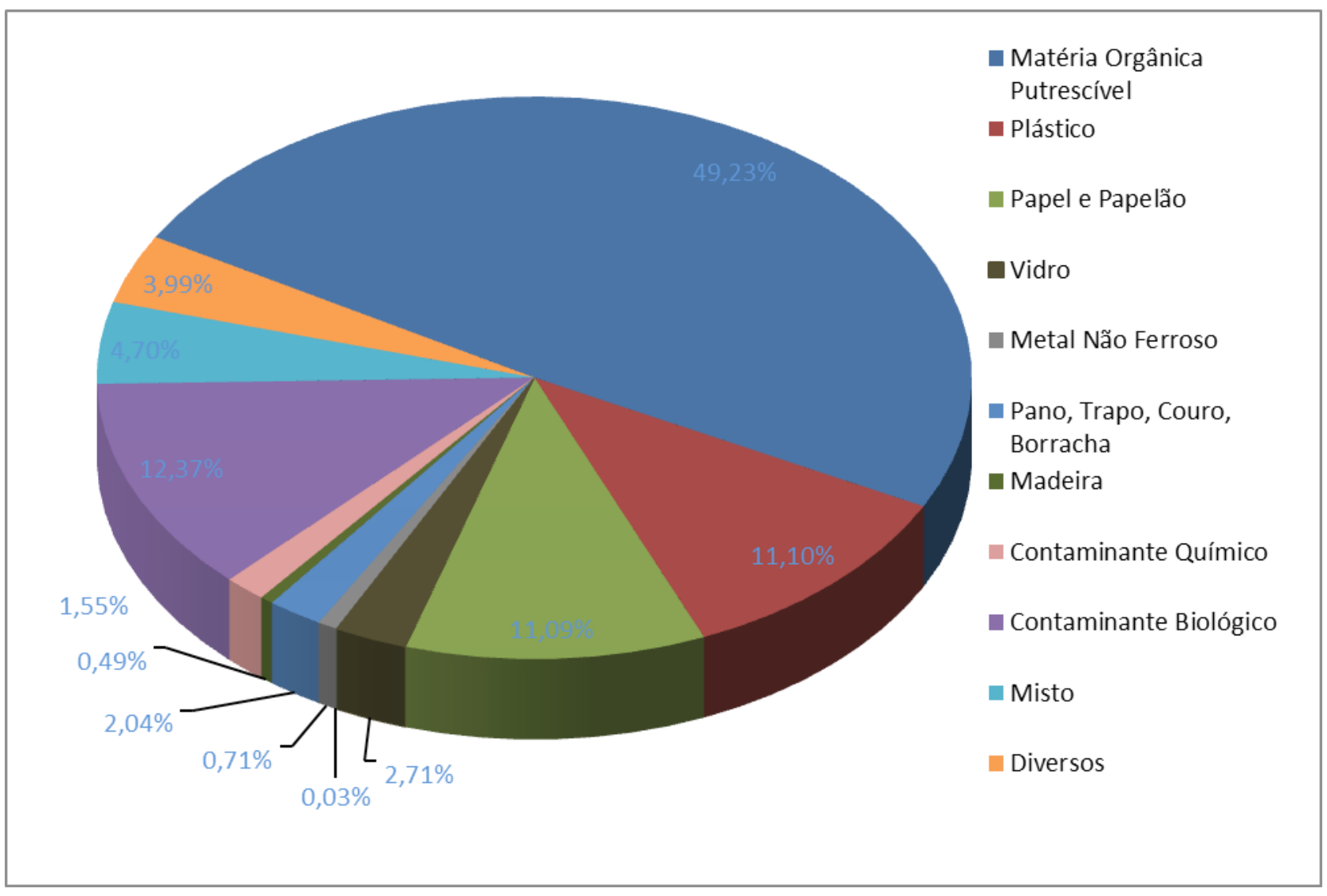

Fonte: Elaboração dos autores.

Em estudo feito em hotéis no Vietnã com 84; 121 e 233 unidades habitacionais apresentam, em média, 5,6\% de componentes recicláveis - incluindo plástico, papel e papelão, vidro e metal (BYER; HOANG; NGUYEN, 2006). Já no hotel em estudo, essa média sobe para 25,63\% do total de resíduos, ou 0,097Kg. pessoa ${ }^{-1}$.dia. Essa discrepância ocorre devido à diferença de hábitos, consumo e riqueza entre as populações de cada estudo. Quando se compararam os valores da composição gravimétrica do presente estudo com os da encontrada para o RSU nacional - contendo 51,4\% de matéria orgânica, 13,5\% de plástico, $13,1 \%$ papel, papelão e tetrapak, e 2,9\% de vidro - notam-se valores bastante próximos com os apresentados na Figura 3 (BRASIL, 2012).

A Figura 4 mostra que $74,86 \%$ dos resíduos gerados no meio de hospedagem estudado possuem alto potencial de reciclagem, seja pela compostagem da 
matéria orgânica putrescível ou pelo reaproveitamento de plástico, papel, papelão, vidro e metais. Por outro lado, os 25,14\% restantes podem ser considerados com potencial de reciclagem limitado, devido à maior dificuldade para a adequada destinação desses materiais - que são os resíduos classificados nas categorias pano, trapo, couro, borracha, madeira, contaminante biológico, contaminante químico, misto e diversos. Dos $74,86 \%$ de resíduos potencialmente recicláveis, 65,77\% refere-se à matéria orgânica e 34,23\% aos secos recicláveis (plástico, papel e papelão, vidro e metais).

Figura 4 - Porcentagem de resíduos potencial de reciclagem limitado e com alto potencial de reciclagem e, dos últimos, porcentagem de matéria orgânica putrescível e secos recicláveis

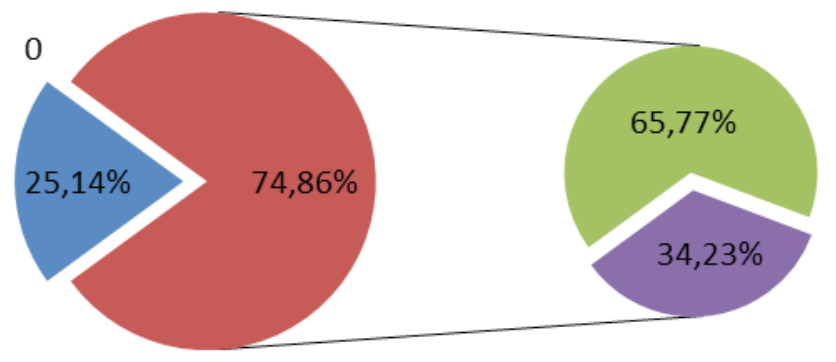

- Potencial de Reciclagem Limitado

alto Potencial de Reciclagem

Matéria Orgânica Putrescível

- Secos Recicláveis (plástico, papel e papelão, vidro e metais)

Fonte: Elaboração dos autores.

As informações sobre os tipos de resíduos gerados em cada serviço, a produção per capita dos resíduos sólidos, as características dos dispositivos de acondicionamento e a segregação dos resíduos são fundamentais para o planejamento do PGRS no setor hoteleiro (DE CONTO et al., 2005). Dessa forma, evidencia-se a importância deste estudo em conhecer as características e a composição dos resíduos gerados em um meio de hospedagem no sul do Brasil. Além disso, pesquisas neste campo auxiliam na definição de melhores alternativas tecnológicas para o gerenciamento dos resíduos sólidos gerados (DE CONTO et al., 
2004). Em Bali, na Indonésia, de acordo com Tang (2004), os hotéis são encorajados a adotar programas integrados de gerenciamento dos resíduos sólidos, sendo os objetivos comuns a redução de impactos ambientais, o aumento da qualidade de vida e a valorização de recursos naturais que, na prática, ocorrem a partir de programas de avaliação quanto ao nível de responsabilidade ambiental (Bali's Eco-hotel Rating Program), que leva em conta instrumentos como o princípio do poluidor pagador e práticas de produção mais limpa.

Salienta-se que a Política Nacional de Resíduos Sólidos prevê a reciclagem, o reaproveitamento e a reutilização dos resíduos e disposição final em aterros sanitários apenas para rejeitos (BRASIL, 2010). Desta forma, o meio de hospedagem possui a necessidade de gerenciar adequadamente os resíduos produzidos em seu âmbito, a fim de oferecer condições para se atingir com eficiência a minimização e a reciclagem dos mesmos.

O Plano de Gerenciamento dos Resíduos Sólidos, além de ser um instrumento de gestão essencial para a conformidade com as necessidades de exploração e disposição de materiais no meio ambiente, é uma ferramenta obrigatória para a adequação de empreendimentos que geram resíduos perigosos ou não perigosos, mas em grandes volumes. Desta forma, os meios de hospedagem brasileiros precisam regularizar-se perante a legislação, buscando criar e implementar um PGRS que venha a enquadrar-se com a política do empreendimento e as necessidades de preservação do meio ambiente.

\section{CONCLUSÕES}

Os resultados obtidos na geração dos resíduos sólidos, no período de alta temporada do meio de hospedagem estudado, caracterizam a composição gravimétrica como uma importante ferramenta para a identificação dos fatores que interferem e determinam a origem e a geração dos resíduos sólidos nesse tipo de empreendimento. Neste estudo, notou-se que a quantidade de pessoas presentes no estabelecimento - hóspedes, funcionários, pessoas extras e em eventos - influencia diretamente no montante de resíduos gerados, bem como na média da geração per capita de resíduos. Esse dado é essencial para o planejamento dos dispositivos de acondicionamento e o setor de 
ISSN: 1983-7151

armazenamento interno do hotel, visto que é possível calcular a quantidade de resíduos gerada no período de maior ocupação do empreendimento, para que assim não haja o subdimensionamento dos dispositivos. Esse tipo de estudo é fundamental para indicar as fragilidades no gerenciamento dos resíduos sólidos e possibilita a criação, a ampliação e a melhoria contínua do PGRS.

A identificação dos setores geradores permitiu reconhecer aqueles que produziam a maior quantidade de resíduos, destacando-se a cozinha - com a matéria orgânica putrescível como resíduo predominante - e, posteriormente, as unidades habitacionais e seus respectivos banheiros e o salão de eventos. A composição gravimétrica média indicou que o resíduo predominante produzido no estabelecimento é a matéria orgânica putrescível - que pode ser destinada à compostagem. Os demais resíduos gerados em maior quantidade foram o contaminante biológico, papel, papelão e plástico. Ainda, uma grande porcentagem dos resíduos gerados no estabelecimento é considerada com alto potencial de reciclagem.

Nesse estudo, foi possível perceber a ocorrência de fragilidades nas etapas do manejo dos resíduos sólidos, em especial na segregação dos resíduos, o que pode estar associada à falta de capacitação dos funcionários, bem como ao número insuficiente de dispositivos de acondicionamento nos setores do meio de hospedagem. Outra limitação constatada no gerenciamento dos resíduos do empreendimento pesquisado consiste na falta de um local planejado para o armazenamento interno dos resíduos que, atualmente, ocorre na garagem.

Conclui-se que as discrepâncias na composição gravimétrica dos resíduos sólidos gerados no meio de hospedagem são relacionadas aos fatores que interferem na geração de resíduos, com destaque para o tipo de evento que ocorre no meio de hospedagem e o motivo da hospedagem. Além disso, o número de hóspedes e pessoas extras e em eventos, como também o setor de geração e as atividades ali desenvolvidas, são fatores que determinam a geração de resíduos sólidos no meio de hospedagem. 
ABRELPE, Associação Brasileira de Empresas de Limpeza Pública e Resíduos Especiais. “Panorama dos Resíduos Sólidos no Brasil - 2012". São Paulo: Grappa Editora e Comunicação, 2013.

AL-JARALLAH, R.; ALEISA, E. A baseline study characterizing the municipal solid waste in the State of Kuwait. Waste Management, v. 34, p.952-960, 2014.

ALMEIDA, M. M. A. Water and waste management in the Marroccan tourism industry: The case of three women entrepreneurs. Women's Studies International Forum, v.35, p.343353, 2012.

BALDUINO, B. C.; BALDUINO, J. C.; MENEZES, P. D. L. La contribucion Del sector de eventos a la hotelaria de João Pessoa (Paraíba - Brasil). Estudios y Perspectivas em Turismo, v.20, p.1497-1512, 2011.

BRASIL. Lei n. 12.305, de 2 de agosto de 2010. Institui a Política Nacional de Resíduos Sólidos; altera a Lei n9.605, de 12 de fevereiro de 1998; e dá outras providências. Diário Oficial [da] República Federativa do Brasil, Brasília, DF, 3 ag. 2010. Disponível em: http://www. planalto.gov.br/ccivil_03/_ato2007-2010/2010/lei/l12305.htm. Acesso em: 06 Abril 2015.

BRASIL. Ministério do Meio Ambiente. Plano Nacional de resíduos sólidos: Versão pós Audiências e Consulta Pública para Conselhos Nacionais. Brasília, 2012. Disponível em: http:// www.mma.gov.br/port/conama/reuniao/dir1529/PNRS_consultaspublicas.pdf. Acesso em: 06 Abril 2015.

BRASIL. Ministério do Turismo. Secretária Nacional de Políticas de Turismo. Estatísticas básicas de turismo, Brasil - Ano 2012. Brasília, 2013. Disponível em: http://www. dadosefatos.turismo.gov.br/dadosefatos/home.html. Acesso em 25 Novembro 2013.

BYER, P. H.; HOANG, C. P.; NGUYEN, T. T. T. Household, hotel and market waste audits for composting in Vietnam and Laos. Waste Management \& Research, v. 24, p. 465-472, 2006.

DE CONTO, S. M. Gerenciamento de resíduos sólidos em meios de hospedagem. In: Trigo, L. G. G. Análises regionais e globais do turismo brasileiro. São Paulo: Roca, 2005, p. 817826.

DE CONTO, S. M.; BONATTO, G.; FELDKIRCHER, E. G.; POSSER, L. Geração de resíduos sólidos em um meio de hospedagem: um estudo de caso. In: CONGRESSO BRASILEIRO DE CIÊNCIA 
ISSN: 1983-7151

E TECNOLOGIA EM RESÍDUOS E DESENVOLVIMENTO SUSTENTÁVEL, 2004, Florianópolis. Anais... Florianópolis: ICTR, 2005. p. 1237-1247.

DE CONTO, S. M.; PESSIN, N.; BONATTO, G.; TELH, M.; CADORE, J.; ROVATTI, D.; BOFF, R.E. Compostagem de resíduos sólidos em meios de hospedagem: prevenção de impactos ambientais em municípios turísticos. In: SEMINÁRIO DE PESQUISA EM TURISMO DO MERCOSUl, 4., 2006, Caxias do Sul. Anais... Caxias do Sul: UCS, 2006. p. 1-14.

DE CONTO, S. M.; PESSIN, N.; PISTORELLO, J.; ZARO, M.; POLETTO, M. Geração de resíduos sólidos em um meio de hospedagem da região uva e vinho no estado do Rio Grande do Sul. In: CONGRESSO BRASILEIRO DE ENGENHARIA SANITÁRIA E AMBIENTAL, 25., Recife, 2009. Anais... Recife: ABES, 2009. 1 CD-ROM

DE CONTO, S. M.; ALVES, T. J. C.; PISTORELLO, J.; PEREIRA, G. S.; PESSIN, R. Las condiciones de saneamiento básico como factor decisivo en la elección del destino turístico: Un estudio basado en la información brindada por los huéspedes. Estudios y perspectivas em Turismo, v. 20, n. 1, p.213-228, 2011 a.

DE CONTO, S. M.; CORRÊA, L. B.; PESSIN, N.; ZARO, M.; PESSIN, R. Espaço para o armazenamento de resíduos sólidos no âmbito de meios de hospedagem: uma necessidade no planejamento de projetos arquitetônicos. In: CONGRESSO BRASILEIRO DE ENGENHARIA SANITÁRIA E AMBIENTAL, 26., Porto Alegre, 2011. Anais... Porto Alegre: ABES, 2011b. 1 CD-ROM.

DE CONTO, S. M.; CORRÊA, L. B.; ZARO, M. Empreendimentos turísticos e a geração de resíduos sólidos: a importância do planejamento de abrigos de armazenamento no projeto arquitetônico de meios de hospedagem. Caderno Virtual de Turismo, v.13, n.3, p.324-340, 2013.

ERDOGAN, N.; BARIS, E. Environmental protection programs and conservation practices of hotels in Ankara, Turkey. Tourism Management, v.28, p.604-614, 2007.

JACOBI, P.; BESEN, G. R. Gestão de resíduos sólidos em São Paulo: desafios da sustentabilidade. Revista Estudos Avançados, v.25, n.71, p.135-158, 2011.

JONES, P.; HILLIER, D.; COMFORT, D. Sustainability in the global hotel industry. International Journal of Contemporary Hospitality Management, v.26, n.1, p.5-17, 2014.

KIRK, D. Environmental management in hotels. International Journal of Contemporary Hospitality Management, v.7, n.6, p.3-8, 1995.

MANDELLI, S. M. D. C. Variáveis que interferem no comportamento da população urbana no manejo de resíduos sólidos domésticos no âmbito das residências. 1997, 267 f. Tese (Doutorado em Educação), Universidade Federal de São Carlos, São Carlos, 1997. 
MARCONI, M. A; LAKATOS, E. M. Técnicas de pesquisa: planejamento e execução de pesquisas, amostragens e técnicas de pesquisa, elaboração, análise e interpretação de dados. 7. ed. São Paulo: Atlas, 2008.

MURPHY, S.; PINCELT, S. Zero waste in Los Angeles: Is the emperor wearing any clothes? Resources, Conservation and Recycling, v.81, p.40-51, 2013.

NEVES, L; GONÇALO, E; OLIVEIRA, R.; ALVES, M. M. Influence of composition on the biomethanation potential of restaurant waste at mesophilic temperatures. Waste Management, v.28, p.965-972, 2008.

PEREIRA, G. S.; DE CONTO, S. M. Manejo de resíduos sólidos en un evento turístico - Fiesta Nacional de la Uva (RS - Brasil). Estudios y Perspectivas en Turismo, v.17, p.119-139, 2008.

PISTORELLO, J.; DE CONTO, S. M. Projeto ambiental em um meio de hospedagem. In: CONGRESSO BRASILEIRO DE ENGENHARIA SANITÁRIA E AMBIENTAL, 26., Porto Alegre, 2011. Anais... Porto Alegre: ABES, 2011. 1 CD-ROM.

SBERT, J. M.; CABELLO, I. R.; OLIVES, E. V.; IRIGOYEN, E. C. The impact of tourism on municipal solid waste generation: The case of Menorca Island (Spain). Waste Management, v.33, p.2589-2593, 2013.

SILVA, R. N. Ações ambientais em meios de hospedagem da Região Uva e Vinho da Serra Gaúcha - RS. 2007, 157 f. Dissertação (Mestrado em Turismo), Universidade de Caxias do Sul, Caxias do Sul, 2007.

TANG, J. A case study of a hotel solid waste management program in Bali, Indonesia. 2004, 178 f. Dissertação (Mestrado em Ciências Ambientais), University of Waterloo, Canada, 2004

VERGARA, S. E.; TCHOBANOGLOUS, G. Municipal Solid Waste and the Environment: A Global Perspective. The Annual Review of Environment and Resources, v.37, p.277-309, 2012. 